\title{
The first orthodontic diploma
}

W. J. S. Kerr, ${ }^{1}$

\begin{abstract}
The advent of the Inter-Collegiate Membership in Orthodontics in the year $\mathbf{2 0 0 0}$ will mark the end of an orthodontic diploma specific to the Royal College of Physicians and Surgeons of Glasgow. The Diploma in Dental Orthopaedics (RCPS) was the first orthodontic diploma in the United Kingdom. The fact that such a diploma has existed first as a DDO and latterly as the MDO (Membership) for some $\mathbf{5 0}$ years is remarkable in view of the relative infancy of most dental specialties and the fact that the General Dental Council has instigated a specialist register in orthodontics as recently as 1998. It was 1965, before other specialty diplomas became available in the British Isles, with the introduction of the FFD by the Royal College of Surgeons in Ireland.
\end{abstract}

$\mathrm{T}$ he decision to develop an orthodontic diploma is recorded in the minutes of the Dental Committee of the Royal College of Physicians and Surgeons of Glasgow ${ }^{1}$ on 18th June 1948 and the regulations for an examination were subsequently approved by the College Council ${ }^{2}$ and the Dental Board of the United Kingdom (the forerunner of the GDC) later that year. There had been recognised orthodontists in the UK since the early part of the century, acknowledged by the formation of the British Society for the Study of Orthodontics (BSSO) in 1907. Matthews ${ }^{3}$, however, states that there were only 10 specialists engaged in the full time practice of orthodontics in 1944, although the BSSO transactions show that there were almost 100 members in London alone at that time. It is important to note, however, that the professing of an interest in orthodontics as distinct from full time practice of the specialty was sufficient to become a member. Only 5 Scottish members are listed at that time.

The BSSO $^{4}$ had earlier commissioned a committee whose remit was, in part, to make recommendations on postgraduate orthodontic teaching. The majority report recommended the setting up of postgradu-

${ }^{1}$ University of Glasgow Dental School,

378 Sauchiehall Street, Glasgow G2 3JZ

REFEREED PAPER

Received 25.10.99; ACCEPTED 22.11.99

(C) British Dental Journal 2000; 188: 299-300 ate orthodontic training either in dental schools generally, or in one or two special centres. A one year training was advised to be marked by the awarding of a diploma on completion. Perhaps due to the war and the subsequent introduction of the National Health Service in 1948 the report does not appear to have been acted upon in any meaningful way until the Glasgow Diploma materialised in 1949 and simultaneously the opening of a Department of Orthodontics at the Eastman Dental Hospital in London. The Royal College of Surgeons of England, however, did not establish a Diploma in Orthodontics until 1954.

The prime mover behind the Glasgow Diploma was Dr (later Professor) James Aitchison (Fig. 1), who was at that time Director of the Dental Hospital and a member of the Dental Committee of the College. The choice of name for the diploma (Diploma in Dental Orthopaedics) remains something of a mystery except that the synopsis of the examination contains the phrase 'including corrective exercises, cervico-facial orthopaedics and mechanotherapy'. The idea of functional jaw orthopaedics had its root in the belief that environment (or lack of function), rather than genetics, was the principal cause of malocclusion and that exercises of the facial and oral musculature could produce effective and permanent changes in the occlusion and facial morphology. This

\section{In brief}

- It is now more than 50 years since the introduction of the first orthodontic diploma in the UK (Diploma in Dental Orthopaedics, RCPS).

- The advent of the Inter-Collegiate M.Orth in June 2000 has prompted investigation of the origins of the first orthodontic diploma.

philosophy was popularised in Europe in the 1930 s by Andresen and Häupl ${ }^{5}$ and would have been à la mode in the post-war period. It is interesting to note that this theory has undergone a renaissance in the past 10-15 years, the American Journal of Orthodontics changing its name to the American Journal of Orthodontics and Dento-facial Orthopedics in 1986.

The Diploma examination was conceived in two parts - basic science and dental orthopaedics, as was the case until 1989. The syllabus was largely the same as the contemporary one. For example, questions on the written paper of the first 2 diets relate to the 'Andresen' appliance, 'Twin-Wire Arch' and the impacted maxillary canine. Whilst the appliances and approach have been superseded by new designs, techniques and treatment regimes, the questions posed are largely the same as in the contemporary examination. The same paper would still be appropriate by simply changing the appliance names to those in contemporary use, such as 'Twin Block' and 'Straight-Wire Arch'.

The first diet was completed on 21st June 1949 and the Register of Diplomates shows that Elizabeth Morrison Webster and James Aitchison were the first successful candidates. In the column marked, Signature of examiner, each of these candidates has signed opposite their name. Legend has it that they examined each other! This seems unlikely however, as closer inspection of the Register shows that although subsequent candidates have an examiner's signature against their name, the column was originally headed 'Signature of examinee'. This has been altered by hand to read "examiner", presumably after the first diet. A panel of 11 
examiners had also been set up during February and March 1949, including local examiners from the West Scotland such as James Aitchison and Tom White, others from elsewhere in Scotland (e.g. Russell Logan) and a number from England (Watkin and Rix) to avoid accusations of 'parochialism'. According to a contemporary editorial in the British Dental Journal ${ }^{6}$ supportive of the move to set up the Diploma 'parochialism' was rife in British orthodontics. The Journal counselled avoidance of this in the new examination! Consequently, there was an ample choice of suitable examiners available to interrogate Dr Aitchison!

Perusal of the register shows that Thomas Cyril White (later Professor, Dean of the Dental School and Convenor of the Dental Council, RCPS) was successful in the second diet held in November 1949 and Geoffrey Hopkin, for many years head of Orthodontics in the University of Edinburgh Dental School, in 1950. At this time there were 16 BSSO members in Scotland. By 1997 this had risen to 83,61 of whom possessed orthodontic diplomas.

In June 1954 a list of eminent orthodontists (Fig. 2) including, Holly Broadbent, Sheldon Friel, Charles Nord, Clifford Ballard and some members of the DDO examiners panel (Rix, Watkin, Kemball and Marsh) appears as have being awarded the Diploma 'without examination and without fee'. From the outset James Aitchison had lobbied the College Council to have the Diploma awarded without examination to 'dental surgeons of special distinction'. At first the Council refused to accept this plea despite copious correspondence and meetings with Dr Aitchison. However by 1954 they relented, but by then most of the local examiners, whom Aitchison no doubt had in mind as being of 'special distinction', had already sat the examination.

At the outset only 6 months full-time experience in orthodontics was required to sit the examination following upon 2 years post 'LDS or equivalent' general dental experience. The BDS was generally still in its infancy and the LDS was the norm as the primary dental qualification. The period of exposure to orthodontics is remarkably

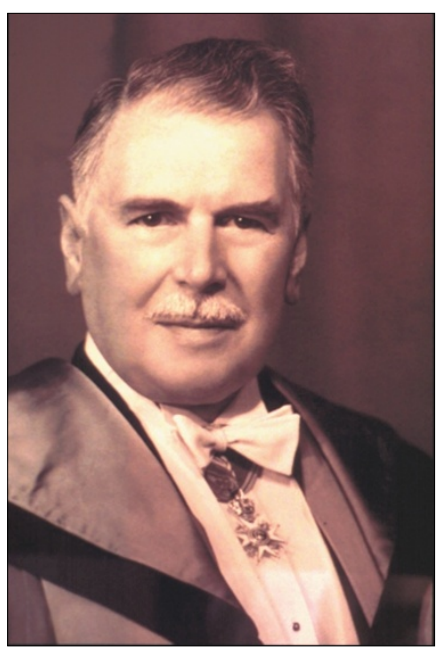

Fig. 1 Dr James Aitchison

brief by present standards, and in view of the BSSO report, when one considers the average length of a course of orthodontic treatment. At the same time it is unlikely that many of the initial candidates were novices going by their ages as recorded in the register, (James Aitchison was 50 and Tom White 39). Three years full-time training became mandatory in 1989 when the Diploma became the Membership, coming into line with the requirements of the European Union. Prior to this the required training period had moved first to one year and then to two years in 1978.

When the London Diploma was introduced in 1954, excluding those without examination, there were 36 holders of the Glasgow Diploma. By the time the Diploma was superseded by the Membership this had risen to 245. Prior to 1954, apart from those closely associated with the Diploma, there was not a rush from the orthodontic estab-



Fig. 2 Extract from the Register of Diplomates, 1954 lishment to submit themselves for the examination. Nevertheless, many of the orthodontists to become influential in the next 20-30 years of the specialty obtained the Diploma - e.g. Barry Leighton, Peter Burke, Jimmy McEwen all to become Professors in due course, as well as Jim Keith from Dublin, later to become Dean of the Faculty of Dentistry (RCSI).

The Edinburgh College introduced its Diploma in Orthodontics in 1987 and Membership in 1989. Since then there has been a degree of rivalry between Colleges in an attempt to attract candidates in an increasingly competitive market. It is fair to say that latterly the Glasgow examination has fared less well in attracting candidates than the other Colleges for a variety of reasons, including lack of exemptions to the written section of the examination and the retention of the practical examination, which has been for some time a unique feature. The Inter-Collegiate M.Orth has arisen out of this rivalry in an attempt to produce a national standard, although at present only the Glasgow and London Colleges are fully involved. The format for the new examination does not differ greatly from the well tried formula of its constituent Colleges' examinations. It does, however, formally recognise the role of the MSc in orthodontic training, reinforcing the importance to the specialty of a sound academic and research base. It is to be hoped that the new examination will enjoy as illustrious a future as the Glasgow Diploma has in the past.

I should like to thank Dr James Beaton and Ms C Parry of the Royal College of Physicians and Surgeons of Glasgow for their help in making available the relevant documentation from College archives.

1 Minutes of Dental Committee, Royal College of Physicians and Surgeons of Glasgow, $1948 / 49$

2 Minutes of College Council, Royal College of Physicians and Surgeons of Glasgow, 1948/49.

3 Matthews E. A layman looks at orthodontics, Transactions of the BSSO 54-66, 1944/45.

4 Report of the Special Committee. Transactions of the BSSO, 114,1942/3.

5 Andresen V and Häupl K, FunctionsKeiferorthopädie Hermann Meusser: Berlin, 1936.

6 A diploma in orthodontics, Notes and Comments. Br Dent J 1949 86:72. 